space-time is the death-knell of materialism, but reflection will show that it must be so. If space is not endless, but finite (and this is the essential principle of the Riemannian geometry), and if time is not in its existence independent of space, but co-ordinate with the spatial dimensions in the space-time system (and this is the essential principle of the concept of the four-dimensional continuum), then the very foundation of the materialistic concept is undermined. Fnr the concept of relative space-time systems the existence of mind is essential. To use the language of philosophy, mind is an a priori condition of the possibility of space-time systems; without it they not only lose meaning, but also lack any basis of existence. The co-ordinations presuppose the activity of an observer and enter into the constitution of his mind. If "you distinguish, as, of course, you must and do, the observer from his space-time system, it is not a distinction of two separate existences externally related; they exist only in their relation, as when, for example, we distinguish an activity from its expression.

This is not a metaphysical gloss on a scientific principle, nor is it an attempt, as some may think, to obstruct the clear path of scientific progress with speculative cobwebs; it is the plainest matter of fact. Everyone who ignores it will simply find himself left stranded, unable to play any part in the conquest of the new realm opening before science.

In fact, it is not from philosophy, but from science, that this rejection of materialism comes. No one has expressed it with greater force and with fuller conviction of its fundamental importance than Prof. Weyl. 'In the introduction to the book which I have quoted, the whole of which is devoted to an exposition of the principle of relativity, he says :-

Whatever matter might ultimately prove to be, one thing we have always felt we knew for certain: that it is a substance underlying all change, and that every bit of matter could be measured as a quantity. Its substantial character found expression in a law of conservation. We believed the quantity of matter remained constant throughout all change. Till now philosophy has usually regarded this as a priori knowledge, unrestricted alike in its generality and in its necessity. To-day the certainty is changed to doubt. After physics in the hands of Faraday and Maxwell had set up another character, the field, above that of matter, and after mathematics on the other side, burrowing during the last century in a logical exploration beneath the basis of Euclidean geometry; had destroyed our confidence in its evidence, there has burst in our days a revolutionary storm which has swept away the ideas of space and time and matter, which till now had been the firmest supports of natural knowledge,-only, however, to make room for a freer and deeper insight into things.

Materialism is essentially a monistic and atomistic conception of reality. For it matter is primordial, and mind is derived. Philosophers from the beginning of philosophy have been conscious of the intellectual difficulty of such a concept, but it has always seemed, even to philosophers, a necessary presupposition of physical science. Science, it was conceded, must at least proceed as if it were so. The principle of relativity is the rejection of it, a rejection based on the discovery, not of theoretical difficulties, but of practical matters of fact. The supposed fundamental reality on which materialism as a world-view was supported has proved a vain illusion, and materialism is left in the air. The new scientific conception of the universe is monadic. The concrete unit of scientific reality is not an indivisible particle adversely occupying space and unchanging throughout time, but a system of reference the active centre of which is an observer coordinating his universe. The methodological difference between the old and the new is that mathematics is a material, and no longer a purely formal, science.

\title{
Damascene Steel and Modern Tool Steel.
}

THREE years ago Col. N. T. Belaiew presented to the Iron and Steel Institute the results of a very careful study of the general properties and structure of Damascene steel, and pointed out the great claims it had to the attention of all those interested in tool steel. He has now contributed a second paper, entitled "Damascene Steel," to the proceedings of the institute, September, I92 I, in which an endeavour is made to substantiate this statement, especially as regards high-speed steels. In his view a marked analogy exists in the structure and also in some of the properties of both types of steel, and a comparative study, therefore, will probably prove beneficial in explaining the properties of these materials and improving the qualities of existing rapid-cutting tools.

Damascene steel belongs to the hypereutectoid series of carbon steels with an average content NO. 27 I2, VOL. IO8] of about $\mathrm{I} \cdot 5$ per cent. of carbon. This carbon exists as iron carbide, $\mathrm{Fe}_{3} \mathrm{C}$, the well-known cementite; $\mathrm{x} .5$ per cent. of carbon represents 22.5 per cent. of cementite; about one-half of this is present with ferrite as the eutectoid pearlite; the remainder forms excess or free cementite. Of this the latter is distinctly the coarser, and in order to globularise or spheroidise the plates in which it exists in the casting, repeated careful hammering and heating are necessary. In this operation the plates are first broken down into small, irregularly shaped crystals, and are afterwards spheroidised, being of such a size that surface tension is able to exercise a marked influence on their ultimate form. The completeness of this spheroidisation is shown in the photomicrograph of an Indian Damascene blade contained in the author's paper, in which the large spheroids have resulted from free cementite, while 
the small ones have been obtained from the eutectoid cementite. In the author's first paper it was shown that a large amount of mechanical treatment was needed in order to produce this complete spheroidisation. The macrostructure shows that the cementite vein runs close up to the edge, and the Oriental maker must have relied most upon securing the best cutting properties in the cementite particles.

High-speed tool steel, which is an alloy steel containing from 16 to 20 per cent. of tungsten and from 3 to 5 per cent. of chromium, in addition to a carbon content not exceeding 0.75 per cent., together with vanadium up to I per cent., also belongs to the cementitic series of steels, and its structure in the annealed condition is strikingly similar to that of Damascene steel. Spheroidised carbide particles are embedded in a sorbitic matrix. To produce the characteristic high-speed hardness such steels have to be heated to incipient melting and then rapidly cooled in a current of air. Even after this treatment a certain amount of carbide remains undissolved, and there are indications that a moderate amount of it increases the cutting properties of the tool. What is important to notice is that the makers of high-speed steel emphasise the necessity of producing a particular type of structure under the hammer, and that during this operation the massive carbides and tungstides present in the ingot are broken down and uniformly distributed through it. Accordingly the ingots are first hammered into billets, and the latter are reheated and hammered a second time. This double treatment is indispensable and must precede the heat treatment proper by thoroughly breaking up and distributing evenly the carbides and tungstides throughout the steel.

Col. Belaiew then compares not only the structures, but also the respective processes of manufacture, and points out how similar they are. Both start with a cementitic steel; both require the greatest care in breaking and evenly distributing the carbides under the hammer; in both cases the amount of mechanical work done on a given article is very large; in both cases the structure of the resulting carbides is globular or spherulitic, while the matrix is martensitic; in both cases the cutting properties of the edge depend both on the matrix and the carbides, and the author is disposed to think that the rôle of the latter is the more important of the two. His studies in this field have led him to the belief that the workers in Damascene steel, while very strict as regards the hammering temperatures, did not lay anything like so much stress on the subsequent heat treatment.

In Damascene steel the degree of spheroidisation is always very high. This was not an end in itself, but was attained incidentally by the numerous cautious forgings and heatings which were designed to produce the greatest ductility possible. In high-speed tool steels spheroidisation is also attained, but the author holds that insufficient stress has been laid on this point by both makers and users, and that the scientific application of the spheroidising process would help to improve the qualities of existing steels. $\mathrm{He}$ considers also that another inference might be drawn from the Damascene process, namely, the proper study of the macrostructure in all cases. An Oriental maker would never manufacture a steel article without having satisfied himself by studying the "watering" that the distribution of the carbide particles was the best possible and in accordance with the shape and properties of the article. Neither would he find a buyer ready to accept a sword or a tool without a proper metallographic examination of it as a whole, and to this the Oriental watering lent itself well. The author suggests, therefore, that a proper examination of the watering of high-speed steel, whether in billets or in the finished article, should prove useful. It is interesting to notice that he found a certain degree of high-speed hardness in Damascene steel itself. This point would repay investigation, for if confirmed it would prove that; at any rate in certain cases, the use of alloy steels is unnecessary, and that they could be replaced by the cheaper carbon steels.

\section{Obituary.}

Dr. Julius Hann.

$T_{\text {the death of Hann, which was briefly noted in }}^{H}$ from the meteorological world the most prominent figure of the past generation and the most productive of all contributors to that branch of science. Hann was born at Schloss Hans, near Linz, in Austria, on March 23,1839 , and his youth was spent in the Alps at Kirchdorf, in Kremstal, some thirty miles south of Linz. After taking his degree in mathematics and physics, he took up a professional career as teacher of those subjects in the high school of Schottenfeld, Vienna, and afterwards at Linz. At the age of twenty-nine he was appointed on the staff of the Central Anstalt NO. 2712 , VOL. IO8] für Meteorologie at Vienna, which was then under the direction of Carl Jelinek. He succeeded Jelinek as director in 1874 , and continued in office until 1897 , when, at the age of fifty-eight, he gave up the appointment and retired to Graz, in Styria, in order to pursue his studies in meteorology; but, finding Graz inconvenient for that purpose, he returned to Vienna in 1900 , and thereafter, as professor in the university, he occupied a room in the Central Anstalt on the Hohe Warte, and continued to work there until the end of his life.

Hann's chief and most continuous occupation was the editing of the Meteorologische Zeitschrift, which, in conjunction with Jelinek, he started on May I, I866, as the Zeitschritt der Oesterreichischen 